\title{
INNOVATION AND ENTREPRENEURSHIP: WHAT PROFESSORS FROM LEADING UNIVERSITIES SAY?
}

\author{
Manuel Oliveira \\ Faculdade de Economia, Universidade do Porto, Rua Dr. Roberto Frias, 4200-464 Porto, Portugal; \\ manueloliv@gmail.com \\ João José Pinto Ferreira \\ INESC Porto, Faculdade de Engenharia, Universidade do Porto, Rua Dr. Roberto Frias, s/n 4200- \\ 465 Porto, Portugal; jjpf@fe.up.pt \\ Hortênsia Barandas \\ Faculdade de Economia, Universidade do Porto, Rua Dr. Roberto Frias, 4200-464 Porto, Portugal; \\ barandas@fep.up.pt
}

\begin{abstract}
As innovation is essential for the competitiveness of enterprises and economic development there is a question which has been raised with some insistence: Do teaching practices make a difference to innovation and entrepreneurship in the work place? Experts were contacted for their views. They say yes, as long as the teaching method is adequate. So, in the USA, a naturally innovative society, a new concept of integrated teaching was developed - "hands-on" to increase innovation ever more in North America. This concept proved also to be successful in a non-innovative society as is demonstrated by the case of MIETE (a partnership between FEUP and FEP, University of Porto) in Portugal.
\end{abstract}

\section{INTRODUCTION}

Innovation enhances employment and society through its improvement of competitiveness. "The importance of promoting innovation has been elevated up to a status of official standard since the Lisbon European Summit in 2000" and "the strategic goal was put forward for Europe to become the most competitive and dynamic knowledge-based economy in the World over the next ten years" Teixeira (2004, p.1-p.2).

However, concerning innovation and entrepreneurship Europe does in fact lag behind the USA. Europe is made up of smaller and more diverse national cultures than the USA, which has achieved a higher rate of technological progress than Europe, and universities of international excellence are seen to play a major part in this (Mateus, 2006).

So, we can ask "What role does the formal teaching of innovation and entrepreneurship play? Indeed, top managers in organizations and industry consistently identify that innovation management and the creation of new products and services is one of their priorities. How then should business and engineering schools go about the teaching of innovation and entrepreneurship? 
We begin the article by reviewing the most salient insights from the literature on innovation and entrepreneurship. Then we move on to interviewee comments. Finally we discuss the case of MIETE, at the University of Porto - a Master's degree which has been a success in an environment with a poor track record concerning innovation and technological entrepreneurship - making reference to the new model adopted by North American universities.

\section{INNOVATION, TECHNOLOGY AND ENTREPRENEURSHIP - SOME INSIGHTS FROM THE LITERATURE}

Inventions are connected to novel ideas for new products or processes, innovation is seen to be the first attempt to put an invention into practice (Fagerberg et al., 2005); as Schumpeter (1934) said, innovation signifies entrepreneurship; and Drucker (1985) defended that innovation and entrepreneurship go hand-in-hand, all successful entrepreneurs are committed to systematically practicing innovation. So, we can't speak of innovation without speaking of entrepreneurship.

Throughout this article entrepreneurship is discussed in view of Shane and Venkataraman's (2000, p.218) definition: “[Entrepreneurship is] a field of business that seeks to understand how opportunities to create something new (e.g., new products or services, new markets, new production processes or raw materials, new ways of organizing existing technologies) arise and are discovered or created by specific persons, who then use various means to exploit or develop them, thus producing a wide range of effects". And, according to COTEC, those persons must have the capability to implement. The authors were thus motivated to contribute to the understanding of the mechanisms that can contribute to its development and with this paper we seek to reflect specifically upon the role of teaching in the development of innovation and entrepreneurship.

Innovators and entrepreneurs - are they born or made? And what is the role of personality? These questions don't cease to incite controversy in the literature.

It may well be that entrepreneurs have special characteristics determined at birth but there seems to be a widespread view in the literature that they can be nurtured, especially through education. An earlier paper published some years ago by Ulrich and Cole (1987) stated that to want to learn throughout one's life and to be interested in education is essential for any entrepreneur. Gorman, Hanlon, and King (1997) indicate that their ten year literature review found considerable support for the teaching of entrepreneurship educational programs can influence entrepreneurial characteristics. Kolvereid and Moen (1997) confirm this. Later, Henderson and Robertson (1999) found that educationalists can affect students and subsequently entrepreneurship as a career choice. More recently, Peterman and Kennedy (2003) confirmed with their research that exposure to entrepreneurship education makes a positive difference to perceptions of desirability and feasibility. Teixeira (2007) agrees also that more successful entrepreneurs could result if they were better targeted by the education system and then nurtured accordingly.

Teaching entrepreneurship is even more relevant in the case of technology-based entrepreneurs, as stated by Storey and Tether (1998, p.1057) who wrote that "The characteristics of technology-based entrepreneurs are also fundamentally different from those in conventional sectors - they are much more likely to be highly educated" and "new technology-based firms have the potential to fundamentally transform the ways in which societies and markets operate. They are, quite simply, crucial to the long term development of an economy and in this sense deserve special treatment... There is a case for governments to take new technology-based firms more seriously... European policymakers... look enviously at the experience of the United States." (ibid.). 
The literature points to the consensus of the importance of education to stimulate entrepreneurship. The same can't be said of the importance of an entrepreneurial personality type, where views diverge. In actual fact, personality, despite being important, is not in itself a sufficient condition to be entrepreneurial. A number of studies have identified an array of important characteristics and we can't confirm that there is a specific type of profile for the entrepreneur.

For example, authors such as Drucker (1985) and Gartner (1988) believe that the personality of the entrepreneur is not relevant and that literature on personality characteristics of the entrepreneur since McClelland (1961) has been unfruitful. In the quest to understand the phenomenon, so many traits related to the entrepreneur have been identified, such as the need for achievement, locus of control, risk taking, values and age, that a sort of generic "Everyman" has been the result; so "Who is an entrepreneur?" may well be the wrong question (Gartner, 1988). We need, according to this latter author, to focus on what entrepreneurs do, the behavioural approach - how they unite means of production.

Johnson (1990) and Cromie (2000) disagree with Gartner (1988) saying that the study of the individual's psychological traits and motivational inclinations shouldn't be abandoned. Entrepreneurship is a multidimensional process but "it remains worthwhile to carefully study the role of the individual, including his or her psychological profile (Johnson, 1990, p.48).

It is amidst this debate that this article is written - can teaching practices on courses of innovation and [technological] entrepreneurship make a difference, especially at the university level where personality characteristics will be more stable?

\section{THE OPINION OF RENOWNED EXPERTS}

It is generally accepted that there are situations and conditions in society which stimulate innovation. There is, for instance, a popular saying that states that "the need stimulates ingeniousness and art". Going back to the $15^{\text {th }}$ century Portugal had as a national objective to sail to the Orient by sea and then Prince Henry the Navigator created a centre for scientific research calling a group of mathematicians together to search for a new method of determining latitude (North, 1981); simultaneously the shipping industry was developed in practice to enable to achieve that national objective. At the time the Portuguese Navigation School at Sagres played a major role in the nation's development, as was emphasized also by interviewee José Mendonça. In effect, according to the literature it is possible to positively influence innovation and entrepreneurship if the philosophy is that the objective of teaching is not just to cover subject matter - teaching is for producing change in behaviour, through increased understanding and attitude and skill development (Ulrich and Cole, 1987). This is best achieved if the student is an active participant in which case role plays, simulations and field projects are pedagogical techniques which will work well for innovation and entrepreneurship students (ibid.).

Back to our question - "Can innovation and entrepreneurship be taught?" several experts on teaching, innovation and entrepreneurship were contacted for their views (Table 1). 
Table 1. Experts contacted for their views on teaching, innovation and entrepreneurship (an advanced draft of the paper was sent to the interviewees for veracity confirmation)

\begin{tabular}{|l|l|}
\hline \multicolumn{1}{|c|}{ Name } & \multicolumn{1}{|c|}{ Affiliation and some career information } \\
\hline Alan MacCormack & $\begin{array}{l}\text { Harvard Business School Associate Professor in the areas of technology } \\
\text { and innovation; as a researcher has received awards for excellence; } \\
\text { internationally recognised }\end{array}$ \\
\hline Arménio Rego & $\begin{array}{l}\text { Assistant Professor at the University of Aveiro; Expert on organizational } \\
\text { behaviour, with 27 books published (author and co-author). His papers } \\
\text { have appeared in journals such as Journal of Business Review, Creativity } \\
\text { and Innovation Management Journal, Thunderbird International Business } \\
\text { Review, Business \& Society, Management Research and Journal of } \\
\text { Happiness Studies }\end{array}$ \\
\hline Chris Brewster & $\begin{array}{l}\text { Full Professor at the Henley Management College and at the University of } \\
\text { Reading Business School - has over 20 books published; one of the most } \\
\text { published authors in the international business journals according to a } \\
\text { survey by the University of Chicago (2005) }\end{array}$ \\
\hline José Mendonça & $\begin{array}{l}\text { INESC Porto CEO (INESC Porto is a research laboratory with 300 } \\
\text { employees, 100 of whom have PhDs) and Full Professor at the Faculty of } \\
\text { Engineering, University of Porto; has extensive international experience }\end{array}$ \\
\hline V. Srinivasan & $\begin{array}{l}\text { Adams Distinguished Professor of Management and Director of the } \\
\text { Strategic Marketing Management Executive Program at the Graduate } \\
\text { School of Business, Stanford University; has won best-teacher awards and } \\
\text { has also received numerous awards for research contributions }\end{array}$ \\
\hline
\end{tabular}

Harvard Business School Professor Alan MacCormack stated that "there are lots of very simple mistakes that entrepreneurs make that we can correct. You know, all that stuff which you might call kind of the science of management we seem to have made progress in. We can certainly teach people concepts that would help them be better at considering all of the possible issues that they might meet if they are an entrepreneur. Over the years we've been very good at finding ways to make business more efficient. If I've got one version of Microsoft Office, here are all the techniques I use to understand how to make a better version of Office, here are the new features, here's how to manage developers so that their programming productivity increases. The concepts of flexibility and adaptability, being able to change as you progress - those things can be taught."

Professor Chris Brewster, of the University of Reading Business School and Henley Management College, stated that "as there are a lot of people teaching innovation obviously it can be taught. Whether that is successful is another matter. Given that innovation depends on two factors: the personality and the system, it may make a difference. The personality cannot be taught; but the systems that allow innovation to flourish can be and if the teaching enables companies to understand and change them it will be useful."

Interviewee V. Srinivasan, of Stanford University, which is well known for its link to Silicon Valley start-ups, created a new concept of teaching, hands-on, and with theory given on an as-needed basis, stated that "Our courses as a whole do have an effect on our students, I think. Certainly the U.S. culture is conducive for innovation, and this is particularly true in the Silicon Valley". Lovejoy and Srinivasan (2002) speak of ten years of experience teaching a multidisciplinary product development course, unique in so far as they use the "hands-on manufacture of customer-ready prototypes executed by crossdisciplinary teams of students in a simulated economic competition against benchmark products and against each other." (ibid., p.32). Concerning course content interviewee V. Srinivasan stated that "both the production of coded scientific and technical knowledge versus experience-based know-how (e.g. learning by doing) play a role on innovation courses."

Interviewees also commented on institutions. The USA has an infrastructure which allows them to rapidly experiment in a variety of new fields as they emerge. And cheaply 
experiment with a whole bunch of different potential opportunities to find out which ones are profitable and which ones are not. And this is associated with a variety of different kinds of institutions. For instance, Alan MacCormack said that "I personally don't think that people on average are any smarter here [in the USA]. And I don't actually think they're necessarily any more entrepreneurial. I just think the infrastructure has been set up in a way that you get thousands of experiments. And out of those experiments comes a Google or you know comes an E-bay... And then another thing that America does have going for it is the scale that allows these companies to get big and somewhat dominant and take advantage of network effects. So if you're a Portuguese entrepreneur and you come up with a great idea your first worry probably once you start to get the seeds of success and see some success is you know how do I actually migrate this to a bigger market where I can really take advantage of network effects and not be stuck within a single country within Europe" (Alan MacCormack).

\section{INNOVATION, TECHNOLOGY AND ENTREPRENEURSHIP IN PORTUGAL}

Contrary to North American society, which is culturally innovative and entrepreneurial, Portugal is very badly classified concerning these two characteristics. Portugal had, in 2005, 858 patents in force whilst in the USA there were 1,214,556 patents in force at the same time (World Intellectual Property Organization at http://www.wipo.int/portal/index.html.en). Comparing Resident Patent Filings per Million Population Portugal had, in 2005, 14.97. The USA had 701.08 for the same year (ibid.). And comparing Resident Patent Filings per \$Billion GDP Portugal had, in 2005, 0.82; and the USA had 18.82 for the same year (ibid.). Also and for Total Entrepreneurship Activity (TEA), in 2005, the USA had a figure of $12.4 \%$ while Portugal had a figure equal to $4 \%$ (or three times less (International Entrepreneurship.com at http://www.internationalentrepreneurship.com/)).

In order to explain the above we focus on three of House et al.'s (2004) nine dimensions of culture, as revealed in their study of 62 societies - Performance Orientation, Power Distance and Humane Orientation.

House et al. (2004) report that the USA has a high Performance Orientation society practice of 4.49 (Type A) versus that of, for example, Portugal, which scored 3.60 (leaving it in the lowest category of Type $\mathrm{C}$ countries on this dimension). "Performance Orientation reflects the extent to which a community encourages and rewards innovation, high standards, and performance improvement" (ibid., p.239). Professor Arménio Rego is of the same opinion and during our interview commented that in Portugal "we have really to focus more on merit and on results... Evidently that this has, I believe, some implications for innovation, in the latu sensu."

Power Distance (PDI) is "the extent to which the less powerful members of institutions and organizations within a country expect and accept that power is distributed unequally" (Hofstede, 2001, p.98). In high PDI cultures, such as Portugal (House et al., 2004; Hofstede, 2001), employees are afraid to disagree with their managers (Çakar, 2006). It is, however, divergent thinking that will contribute to innovation capability (ibid.). Again, Arménio Rego, of the University of Aveiro, stated that "Cultures which are very strong in Power Distance, and that is the case of Portugal [unlike the USA], are cultures where innovation can also be less frequent. Why? Do you know what strong Power Distance cultures are? They are cultures where there is difficulty on the part of the subordinates to question their superiors and to collide with the opinions of their superiors. You understand that in a culture with these characteristics it is more difficult for the 
organizational members to make themselves available to present innovative suggestions which collide with the status quo... cultures with high Power Distance, where people feel inhibited to express themselves to their collaborators with the fear of retaliation and/ or so as to not hurt susceptibilities, are cultures which will eventually have smaller propensity for innovation."

José Mendonça, of the University of Porto and CEO of INESC Porto, spoke about the humane orientation and stated that "primarily there may be a cultural and motivation problem in Portugal. In our Mediterranean culture the family structure protects children. It is the parents who pay for the degrees... not banks. And if our children fail a year it will not be another year they would have to pay the bank back for. So the attitude is different." José Mendonça continued to say that "in Portugal we have risk adverse companies... The State, the government has a very important role to play, especially when they say that thousands of millions of Euros in support etc. are on their way over from the European Commission, etc. of the so-called QREN - National Strategic Reference Framework for the development of Portugal 2007-2013. So, we need a clear, very strict framework to be established of stimulus and orientation which really promote innovation. Not make believe. It is not to cover up support for other types of companies that should go bankrupt." The above examples (parents protecting children in Portugal, and Portuguese government funding being used to avoid unemployment) are reflections of a Humane Orientation, which makes itself evident in caring, altruistic behaviour; being friendly, generous and kind to others (House et al.,2004). Schwartz (1992) goes further to mention protection of all people in such Humane societies, including strangers. Portugal is more Humane than Spain (House et al., 2004) which "managed to, obviously going through hard years and high levels of unemployment, etc. managed to reform the industrial sector and to reform the civil service sector. We didn't do one or the other" (interviewee José Mendonça). These facts have a huge weight on the economy and will mean that companies will not be as innovative and competitive as others.

Cultures which lack a Performance Orientation, are high in Power Distance, and in Humane Orientation, may be less innovative and experience greater problems in companies which abide by more benevolent, conflict-avoiding values.

\section{MIETE: A BRIEF DESCRIPTION. THE CASE OF PORTUGAL}

First of all a brief reference to the new model adopted by North American universities Stanford University (early 1990s) and the University of Michigan (five years later than in Stanford) both offer courses in innovation - Integrated design for marketability and manufacturing (IDMM at Stanford); and Integrated product development (IPD at Michigan). A project is undertaken; student teams have to perform well in each of the Marketing, Manufacturing, Engineering and Design dimensions; hands-on manufacture of customer-ready prototypes is performed; a tradeshow occurs at the end; projects are subjected to a market-based performance test. Of note and concerning results is the fact that commercial firms have purchased the rights for two of the new products developed by student teams over a period of ten years. This model however is not only possible in the USA, as MIETE (a two year Master's course (dissertation included) in Innovation and Technological Entrepreneurship), in Portugal, shows. The objective at MIETE, a similarly hands-on cross-disciplinary course, is to give real training in the innovation process and technology commercialization involving the assembly of a sound and solid business plan (with real commercialization problems) ready to be analysed by investors by the end of the course - the emphasis is on learning by doing taking its participants through the entire venture creation process even if the technology is not commercialized in the end - though 
two companies have already been set up as a result of the course in only three years since it started in 2004 (Oliveira, 2008).

Despite Portugal having been in the past an example of entrepreneurship and a centre of excellence for innovation (Martins, 1901, 1983) currently Portugal, according to The European Commission, in its study Targeted Socio-Economic Research - Strategic Analysis of the European Science and Technology Policy Intelligence, coordinated by R. Barre (Mateus, 2006, p.512), which classified regions according to number of patents per inhabitant, number of scientific papers per inhabitant and GDP per capita, concluded that in the Iberian Peninsula, comprising Portugal and Spain, there are only two regions of Type B - Madrid and Barcelona. Spain and Portugal don't have any regions of Type A, such as London, for example. The most advanced region in Portugal is Lisbon, which is Type C. All other Portuguese regions are of the lowest level possible - Type D.

It is in this context that MIETE, a new concept of teaching, appears in the North of Portugal - in a region of low gross domestic product per capita, with a low number of patents per inhabitant, as well as few scientific publications per inhabitant (Mateus, 2006). And yet MIETE has managed to produce innovative technological companies in just three years. What does MIETE count on to achieve this success?

The MIETE course is a partnership between two faculties and thus resides in the Faculty of Engineering and the Faculty of Economics, both of the University of Porto, in the North of Portugal. Cross-disciplinary teams of students are formed, indeed MIETE is a cross-disciplinary course - it involves faculty from several academic units (Business, Engineering and Design, and any other technological course of the student's choice (thus providing the flexibility to adjust the technical training to the students' needs)) - the course requires faculty with broad interests and experience with real practitioner innovation. Theory is given only when necessary and to support the practical hands-on innovation process. Contact with area specialists Worldwide and cold-calling are encouraged.

The emphasis is on products and corresponding markets. Interaction of its students with researchers from different fields at the University of Porto is promoted. Technologies are chosen by students in contact with the University of Porto R\&D groups. Students are also allowed to follow their own path, their own ideas, and considering interaction with enterprises.

Until now this course has been demonstrated to be a success and two companies have been started as a result of the MIETE course, since its inception, in 2004: Tomorrow Options Microelectronics S.A. (the revolutionary first ever portable product for the prevention of foot diabetes complications, such as foot amputation, WalkinSense, marked the launch of this company. The WalkinSense mechanism may well be used in other areas such as sport, industry, and rehabilitative medicine. Portugal, the UK and then the USA and the rest of Europe are the target markets. An ambitious sales plan has been drawn out - through the year 2012, 20,000 units or more are to be sold, at 2,000€ per unit. The term "pocket multinational" best describes its activities (http://www2.inescporto.pt/uitt/noticias-eventos/nos-na-imprensa/tomorrow-options.html on 05-02-2008).), and IDEAVITY (Mingle is their first project, a unique proposal in mobile social networking, virtual Worlds and communication at an affordable cost).

According to this model MIETE's teaching is based on both theory and practice, on management as a science, giving assignments which broaden, on overcoming uncertainty by promoting uncertain situations requiring flexibility and adaptability to be surpassed, encouraging contact with knowledge leaders, and above all by boosting energy levels of its participants. 


\section{DISCUSSION}

The teachers interviewed for this study are of the opinion that innovation and entrepreneurship can be taught and certainly the literature shows some evidence of this (Ulrich and Cole, 1987; Gorman, Hanlon, and King, 1997; Kolvereid and Moen, 1997; Henderson and Robertson, 1999; Kennedy, 2003; Teixeira, 2007; Storey and Tether, 1998). Lots of very simple mistakes that entrepreneurs make can be corrected and flexibility and adaptability, being able to change as you progress, can also be taught, stated interviewee MacCormack, of Harvard Business School. The influence of market size, institutions and infrastructure, allowing cheap and rapid experiments with potential opportunities, will also be important, MacCormack went on to say. Interviewee Brewster, a prominent author from a leading research university in the UK, pointed to personality and systems as playing a major role in innovation, the systems being able to be taught but the personality being more difficult to change. Interviewee Srinivasan, of Stanford University, says that their courses make a difference, where experience-based know-how (e.g. learning by doing) and theory both play a part.

Interviewee Rego, author of 27 books and numerous scientific articles, of the University of Aveiro, emphasized the importance of culture and having a low power distance and high performance orientation, in society and in organizations. Divergent thinking, being able to disagree with your boss and aiming for results is paramount for innovation to occur. Mendonça, INESC Porto CEO, Full Professor and expert on innovation indicated that more humane societies such as Portugal (and in comparison to its neighbour Spain) which don't want to go through the pain of unemployment will burden the economy with low innovation levels; a strict government framework, of stimulus and orientation, which really promotes innovation, will be needed to remedy this.

Concerning the teaching of entrepreneurship however, interviewee MacCormack, of Harvard Business School, stated that "one of the key elements clearly to a successful entrepreneurial company is associated with the personal characteristics of the founders, their drive and motivation and passion... And you know by definition an entrepreneur has to be somewhat irrational because if an idea was blindingly obvious and didn't require a lot of effort and time it probably would have been done. So an entrepreneur in the initial days probably has to be a bit of a contrarian too... And those are things which, you know, frankly you don't really teach in a classroom." But what if the teaching of innovation and entrepreneurship started earlier, at primary school? If we start encouraging an entrepreneurial spirit earlier, certainly before university (when personalities are more stable and difficult to change) and using the right pedagogical techniques, we may increase the level of entrepreneurship in society. Education can always have an impact but we can also modify personalities to a certain extent if we start early enough. Dreaming of becoming a famous pianist or an accomplished sportsperson may be deemed normal in our youth but why shouldn't children dream of becoming a successful entrepreneur too? Having the right image of what we want to be is essential and this can be encouraged by educators and family members, who, if aided by the media, can create the right messages and long term goals. "Starting earlier offers a lifetime edge" states Goleman (1995, p.79); and as setting up a company that thrives in the global marketplace means being at world class level, as interviewee José Mendonça commented, there may be a parallel between entrepreneurship and the discipline of innovation and other activities (such as violin virtuosos who start at age five and chess champions who start playing chess at age seven (Goleman, 1995)) - the promotion of an entrepreneurial spirit before the personality solidifies may bring benefits to society and as such this may be an issue calling for deeper reflection by policy makers. 
We uphold that innovation and entrepreneurship, as taught by the MIETE course, a program founded on initial cooperation with the North Carolina State University, is a good example of how even in a high power distance society with a relatively low performance orientation the teaching of innovation and entrepreneurship can have a positive impact. MIETE, in an environment which is very different as compared to the USA, focuses on learning-by-doing which goes hand-in-hand with its deep theoretical basis of how innovation can be successful in a small society, where the innovation capability has improved satisfactorily over the last 40 years and especially from 19952001 (Teixeira, 2004). MIETE has had speedy results and this may be due to its requiring adaptation to immediate circumstances as Ulrich and Cole (1987) advocate. Entrepreneurs should be good at implementing plans and engaging in new action-oriented experiences so the learning style of the entrepreneur (ibid.) is catered to by MIETE. Innovation and entrepreneurship can be taught, we believe, if the right pedagogical techniques are used. 


\section{REFERENCES}

1. Çakar, Nigar Demircan. Enhancing innovation capability through human resource practices: an empirical study in Turkish SMEs. South-East Europe Review 2006; 4: 109-126.

2. Cromie, Stanley. Assessing entrepreneurial inclinations: some approaches and empirical evidence. European Journal of Work and Organizational Psychology 2000; 9(1): 7-30.

3. Drucker, Peter. The discipline of innovation. Harvard Business Review 1985; May-June: 67-72.

4. Fagerberg, Jan; Mowery, David, Nelson, Richard (editors). The Oxford handbook of innovation. Oxford University Press, 2005.

5. Gartner, W.B. Who is an entrepreneur? is the wrong question. American Journal of Small Business 1988; 12(4): 11-32.

6. Goleman, Daniel. Emotional Intelligence - Why it can matter more than IQ. Bloomsbury, 1995.

7. Gorman, G., Hanlon, D., King, W. Some research perspectives on entrepreneurship education, enterprise education and education for small business management: a ten-year literature review. International Small Business Journal 1997; 15 (3), April-June: 56-78.

8. Henderson, Roger and Robertson, Martyn. Who wants to be an entrepreneur? Young adult attitudes to entrepreneurship as a career. Education and Training 1999; 41(5): 236-245.

9. Hofstede, Geert (2001). Culture's consequences: comparing values, behaviours, institutions, and organizations across nations. $2^{\text {nd }}$ edition. Sage Publications.

10. House, R.J., Hanges, P.J., Javidan, M., Dorfman, P.W., Gupta, V. (editors). Culture, leadership and organizations - The GLOBE study of 62 societies. Sage Publications, 2004.

11. Johnson, B.R. Toward a multidimensional model of entrepreneurship: the case of achievement motivation and the entrepreneur. Entrepreneurship Theory and Practice 1990; 14(3): 39-54.

12. Kolvereid, Lars, Moen, Oystein. Entrepreneurship among business graduates: does a major in entrepreneurship make a difference? Journal of European Industrial Training 1997; 21(4): 154-160.

13. Lovejoy, W.S., Srinivasan, V. Ten years of experience teaching a multidisciplinary product development course, Journal of Product Innovation Management 2002; vol. 19: 32-45.

14. McClelland, D.C. The achieving society. The Free Press, 1961.

15. Martins, J. P. Oliveira. História de Portugal, 6th edition, Parceria António Maria Pereira, Livraria Editora, Lisboa, 1901.

16. Martins, J. P. Oliveira. Os fillhos de D. João I, Lello e Irmão - Editores, Porto, 1983.

17. Mateus, Abel M. Economia Portuguesa ( $3^{\text {rd }}$ edition). Editorial Verbo, 2006.

18. North, Douglass C. (1981). Structure and change in economic history. W.W. Norton \& Company, Inc.

19. Oliveira, Manuel Teaching innovation - a comparison between courses in Europe and in the USA. Research Seminar article published in the Conference Proceedings of the $18^{\text {th }}$ Luso-Spanish Conference on Management, held at the Faculty of Economics of the University of Porto (7-8 February, 2008).

20. Page, M. The first global village - how Portugal changed the world. $9^{\text {th }}$ edition, Casa das Letras, 2002.

21. Peterman, Nicole E., Kennedy, Jessica. Enterprise education: influencing students' perceptions of entrepreneurship. Entrepreneurship Theory and Practice. Winter, 2003, 129-144.

22. Schumpeter, J.A. "The theory of economic development: an inquiry into profits, capital, credit, interest and the business cycle", (trans. R. Opie), Cambridge, Mass: Harvard University Press, 65-94, in Entrepreneurship (1990), Mark Casson (Ed.), Edward Elgar Publishing Limited, 1934, 105-134.

23. Schwartz, S.H. Universals in the structure and content of values: Theoretical advances and empirical tests in 20 countries. In M. P .Zanna (Ed.), Advances in experimental social psychology, Orlando, FL: Academic Press, 1992; 25: 1-65.

25. Shane, S., Venkataraman, S. The promise of entrepreneurship as a field of research. Academy of Management Review 2000; 25(1): 217-226.

26. Storey, D.J., Tether, B.S. Public policy measures to support new technology-based firms in the European Union. Research Policy 1998; 26: 1037-1057.

27. Teixeira, Aurora C. How has the Portuguese innovation capability evolved? Estimating a time series of the stock of technological knowledge, 1960-2001. Working paper $\mathrm{n}^{\circ}$ 153, Faculdade de Economia, Universidade do Porto, September 2004.

28. Teixeira, Aurora C. Entrepreneurial potential in business and engineering courses - Why worry now? FEP Working Paper $n^{\circ}$ 256, December. INESC Porto, CEMPRE, Faculty of Economics, University of Porto, 2007.

29. Ulrich, T.A., Cole, G.S. Toward more effective training of future entrepreneurs. Journal of Small Business Management 1987; 25(4): 32-39. 